\title{
Unilateral Aural Atresia: Current Management Issues and Results
}

\author{
Brian D. Nicholas $\cdot$ Bradley W. Kesser
}

Published online: 26 March 2013

(c) Springer Science+Business Media New York 2013

\begin{abstract}
Unilateral aural atresia (UAA) presents both diagnostic and therapeutic challenges to the clinician. The absence or stenosis of the ear canal is usually associated with aberrant middle ear morphology and a variable conductive hearing loss (CHL). While the scholastic deficits associated with unilateral sensorineural hearing loss and otitis media with effusion have been well-studied, the disabilities associated with unilateral (or bilateral) aural atresia with its attendant moderate or moderate-severe CHL are less well understood. With the advent of new and more widely and easily accessible implantable hearing devices, more options are available for hearing rehabilitation in patients with unilateral or bilateral aural atresia. Preoperative tools such as high resolution computed tomography and pure tone and speech audiometry are typically used to provide some insight on the middle ear anatomy and thus predict hearing outcomes following surgical atresia repair. In this review, we explore treatment options for patients with UAA, including the use of implantable devices such as bone-anchored hearing devices and implantable middle ear devices. Predictors of success for atresia surgery will be highlighted as these may be the primary measures by which patients are counseled and ultimately choose treatment.
\end{abstract}

B. D. Nicholas · B. W. Kesser $(\bowtie)$

Department of Otolaryngology-Head and Neck Surgery,

University of Virginia Health System, PO Box 800713,

Charlottesville, VA 22908-0713, USA

e-mail: bwk2n@virginia.edu

B. D. Nicholas

e-mail: bnicholas44@gmail.com
Keywords Aural atresia - Conductive hearing loss . Implantable hearing devices - Conductive hearing loss . Unilateral hearing loss

\section{Introduction}

Congenital aural atresia (CAA) occurs in about 1 in $10,000-20,000$ live births [1-3]. Unilateral atresia is far more common than bilateral, on the order of 3-4:1. For unknown reasons, CAA occurs more frequently on the right side, and affects males more often than females. The CAA is marked by the absence or stenosis of the external ear canal, and is usually accompanied by the absence of a tympanic membrane, ossicular abnormalities, and microtia. The primary embryologic abnormality in CAA is failure of the first branchial groove epithelial plate to canalize [4]. Arrest of this process prior to canalization at 6 months gestation results in complete atresia, and arrest during canalization results in incomplete atresia or canal stenosis. Because of the embryologic association between the external ear canal and the first branchial arch, patients with CAA often have a contracted middle ear space and ossicular abnormalities. Likewise, the first and second branchial arches give rise to the axonal hillocks that form the auricle, accounting for the common association between CAA and microtia. Conversely, the inner ear primarily derives from the otocyst rather than the branchial apparatus. As a result, inner ear structures are usually not affected in patients with CAA [5, 6]. In some patients, CAA is associated with a craniofacial syndrome such as Treacher-Collins, hemifacial microsomia, or Goldenhar.

The various classification systems proposed for CAA are based either on a physical exam, imaging, or findings at the time of surgical repair. Altmann initially proposed a 
grading system in 1955 based on the severity of the abnormality [7]. In Group 1 (mild), there is some part of the external auditory canal (EAC) present. In Group 2 (moderate), there is no EAC and a contracted middle ear, and in group 3 (severe), there is no EAC present, and a severely hypoplastic or absent middle ear space. More recent classification systems have focused on high resolution computed tomography (HRCT) imaging findings with the goal of delineating which patients are the best candidates for surgical repair [8, 9]. Jahrsdoerfer's grading system has become widely utilized as a guide for clinicians in determining surgical candidacy. With recent advances in alternative hearing rehabilitation options such as bone conducting devices, there is an increased interest in preoperative measures that may predict successful hearing outcomes in patients undergoing surgical aural atresia repair.

The evaluation of the patient with CAA consists of a history, a physical examination, family history, comprehensive audiometry, and HRCT imaging. The CT allows for the evaluation of the external, middle, and inner ears as well as for the presence of cholesteatoma. Pure tone and speech audiometry should be performed to obtain air and bone conduction thresholds. To account for the masking dilemma in patients with bilateral aural atresia, the sensorineural acuity level (SAL) test should be performed to obtain accurate bone conduction thresholds in each ear. When the child presents as a newborn, electrophysiologic assessment of cochlear function is essential, especially in patients with binaural atresia. If the cochlea appears to be functioning normally — as determined either by auditory brainstem response testing (ABR) or bone conduction thresholds - the child is a candidate for hearing habilitation. In patients with bilateral aural atresia, children should be fitted with bone conducting hearing systems as soon as possible to allow for speech and language development in the critical early years of development.

Long term treatment of UAA presents unique challenges to the clinician, and several different points must be considered when determining the prescribed course of hearing habilitation. Options include observation with preferential seating in school, surgical reconstruction of the EAC, tympanic membrane and ossicles, and an ever-growing list of implantable and semi-implantable hearing devices.

Optimal treatment of children with UAA is controversial, and there is great debate among clinicians with regard to conservative versus operative management. Whereas patients with bilateral conductive hearing losses have evident functional impairments, the functional deficits of a unilateral conductive hearing loss are much less understood. The functional, academic deficits of unilateral sensorineural hearing loss in school-age children were first outlined by Bess and Tharpe in 1984 and have been well documented in numerous studies since that time [10-14]. It has recently been proposed that a unilateral conductive hearing loss may also result in significant functional deficits in some patients as the brain is deprived of binaural input [15-17]. Though no clear critical period for supplying binaural input to the brain has been elucidated, there is some evidence that children with unilateral conductive deficits may have abnormal binaural processing even after correction of the hearing loss [18].

The surgical repair of CAA presents a challenge to the otologic surgeon due to the wide variation in middle ear anatomy and the unreliable position of surgical landmarks. A further challenge is the concurrent presence of microtia, because the surgical reconstruction of the auricle may determine the timing of surgical atresia repair. This review outlines options for hearing habilitation, with a specific focus on recent publications updating outcomes, predictors of success, and newer implantable hearing devices.

\section{Surgical Repair}

Surgery to restore hearing in patients with CAA dates back at least to Kiesselbach in 1883, though there has been some suggestion that procedures to correct aural atresia were performed as early as the Byzantine era [2, 19]. By the 1950s, reports detailed surgical correction of CAA, and in 1971 Nager advocated an approach customized to the severity of the congenital malformation [20-22]. Early approaches as described by Nager and Schuknecht [22, 23] largely focused on accessing the middle ear through the mastoid to achieve either a lateral semicircular canal fistula or to perform a type III tympanoplasty. Jahrsdoerfer [2] was the first to describe an anterior approach which allowed for the removal of the bony atretic plate and mobilization of the ossicular chain. This approach avoided exposing the mastoid air cells, reducing the chance that the newly created ear canal would be plagued by drainage. In this approach, the tegmen and posterior aspect of the temporomandibular joint are followed medially through the non-pneumatized bone, and the atretic plate is removed, with care taken not to transmit the high energy of the drill to the ossicular chain. The ossicular chain is mobilized, an onlay temporalis fascia graft tympanoplasty is performed, and the canal is lined with a split-thickness skin graft (STSG). The STSG has traditionally been harvested from the patient's ipsilateral upper arm, though it has recently been suggested that the scalp may be a suitable donor site that is within the primary surgical field [24].

Surgery to reconstruct the atretic ear is usually delayed until the patient is 5-7 years old, though it can also be performed in adulthood. The timing of the surgery is, in part, dependent on the concurrent presence of microtia and 
whether and by what method the auricle is reconstructed. In those patients undergoing microtia repair with an autologous costal cartilage graft, the atresia surgery is typically delayed until the final stage of microtia repair so as not to compromise the integrity of the vascular bed for the autograft. However, if a patient chooses to undergo microtia repair with an allograft such as porous high-density polyethylene $\left(\right.$ Medpor $^{\circledR}$, Porex, Newnan, GA), atresia repair is performed before the auricular reconstruction. In the short term, hearing results for atresia surgery performed before Medpor $^{\circledR}$ have compared favorably to hearing results in patients undergoing atresia surgery after autologous costal cartilage auricular reconstruction [25]. This paradigm has been modified recently, as some have suggested that even in cases where costal cartilage is used, the atresia repair can be performed concomitantly with microtia repair with excellent hearing and graft survival results $[26,27]$.

Jahrsdoerfer devised a grading scale to determine which patients were to be considered suitable candidates for surgery [8]. High-resolution computed tomography (HRCT) was used to give ears a numerical score based on the presence of middle and outer ear anatomy. Patients with unilateral CAA and a Jahrsdoerfer score of seven or greater, and those with bilateral CAA with a 5-6 or better, were considered candidates for surgical repair. Both the anterior surgical approach and the grading scale have become widely used among otologic surgeons performing atresiaplasty.

Published reports of hearing results after atresia repair abound, but reports of long-term hearing results are scarce. A recent study by Shonka et al. [28.] found that $89 \%$ of patients with a Jahrsdoerfer score of seven or higher had 4-6 week postoperative speech reception thresholds (SRT) $\leq 30 \mathrm{~dB}$ HL. In that study, only $45 \%$ patients with a Jahrsdoerfer score of 6 or below achieved a postoperative SRT $\leq 30 \mathrm{~dB}$ HL. Long-term hearing outcomes demonstrate some stability of the initial results; Lambert found that $64 \%$ of patients maintained a postoperative SRT $\leq 30 \mathrm{~dB}$ HL at least one year after surgery [29]. Likewise, De La Cruz and Teufert [30] achieved air-bone gap (ABG) closure to $30 \mathrm{~dB}$ in about $50 \%$ of cases with long term ( $>6$ months) follow up. Not only do hearing results seem to be relatively stable over time, but the results have improved with advances in surgical technique [31]. An important caveat to the outcome data, however, is the lack of uniformity in patient selection from study to study. Not all reports use the same inclusion criteria, with some having a more broad inclusion (e.g., primary and revision cases) with others using stricter criteria (e.g., Jahrsdoerfer score $\geq 7$, primary cases only).

While published reports of hearing outcomes are common, there is a relative paucity of quality of life measures for patients with UAA. A recent study by Ren et al. [32] outlines a new and validated quality of life questionnaire specifically for patients with CAA. In the future, this may be used as an adjunctive outcome measure for success with atresia repair.

Complications from atresia repair surgery range from the very rare facial nerve injury and sensorineural hearing loss, to the more common meatal/canal stenosis and chronic drainage. Stenosis of the external auditory meatus or canal $(58 \%)$ and drainage $(20 \%)$ were found to be the most common complications in a series of patients undergoing revision atresia surgery [33]. A recent study by Moon et al. [34] has suggested the employment of a longterm ear canal stent to reduce the risk of postoperative canal stenosis.

\section{Predictors of Surgical Success}

With the emergence of improved options for hearing rehabilitation, there has been an increased focus on identifying preoperative measures that can be used to predict success in atresiaplasty. As mentioned, Shonka et al. [28•] found that the Jahrsdoerfer score proved to be an excellent predictor of postoperative hearing success.

There remains, however, wide variation in hearing outcomes among patients with the same Jahrsdoerfer score. Previous reports have indicated that one particular aspect of the Jahrsdoerfer grading scale may itself be predictive. The degree of middle ear aeration was found to be the only anatomic predictor of success in a series of 116 atretic ears [28•]. This finding was corroborated by two recent studies that found middle ear aeration and volume to be predictive of success following atresia repair $[35 \cdot, 36]$.

In an effort to identify other predictors of success aside from anatomy/preoperative imaging, a recent series of 133 atretic ears found preoperative hearing to be a strong predictor of postoperative hearing [37]. These findings suggest that the preoperative audiogram may reveal something about middle ear anatomy not otherwise seen on preoperative HRCT. The great variation in the morphology of the ossicular chain may in part explain the variability in hearing outcomes [38]. A recent report suggests that the angle of articulation between the incus and stapes may account for variation in hearing outcomes after atresia repair. In a large series, Kim et al. [39॰] demonstrated that an incudostapedial (IS) angle closer to $90^{\circ}$ was found to be predictive of better postoperative hearing when compared to more obtuse IS angles. It is likely that small differences in the ossicular morphology may account for the variance in postoperative hearing among patients with the same preoperative Jahrsdoerfer score. Future studies will attempt to correlate form with function-middle ear and ossicular anatomy with postoperative hearing results. 


\section{Bone Anchored Hearing Devices}

In addition to atresia repair, a bone conducting hearing aid may be worn around the head on a hard metal band or a soft band, or a bone anchored hearing device can be implanted in the calvarium. These osseointegrated titanium implants were first introduced in the 1980's and couple the implant to a hearing aid (bone oscillator) through a percutaneous abutment [40]. Two commercially available systems of bone anchored hearing devices exist, the BAHA $^{\circledR}$ (Cochlear Americas, Centennial, CO) and the Ponto ${ }^{\circledR}$ (Oticon Medical Corp., Somerset, NJ). These devices are FDA-approved for children 5 and older in the United States. In younger children, a BAHA ${ }^{\circledR}$ or Ponto ${ }^{\circledR}$ softband, a bone conducting hearing aid worn on a band not coupled to an osseointegrated implant, may be used.

The surgery required to implant an osseointegrated device requires far less time than reconstructive atresiaplasty. In addition, whereas aural atresia repair is widely considered one of the most technically challenging cases in otology, the implantation of a bone anchored hearing device is a quick and straightforward procedure. There are, however, complications associated with the titanium post, most notably, skin overgrowth and infection. Additionally, the cosmesis of a bone-anchored hearing aid is significantly inferior to a reconstructed auricle and meatus [41].

There are several published reports on the successful use of bone-anchored devices in bilateral aural atresia [42-44]. There have been fewer published reports, however, of bone anchored hearing devices in patients with unilateral aural atresia, perhaps because the functional hearing deficit in this population is not fully understood. However, as noted above, there is some data to suggest a significant functional deficit may arise from a unilateral sensorineural or conductive hearing loss [10-18]. Thought to be due to the deprivation of binaural input at an early age, these data provide some of the basis on which early fitting with a bone conducting hearing aid may be advocated for children with unilateral aural atresia.

Kunst et al. [15] found mixed results in terms of sound localization and hearing in noise among patients with unilateral conductive hearing loss after BAHA ${ }^{\circledR}$. Bouhabel retrospectively compared hearing results among patients who had undergone BAHA ${ }^{\circledR}$ versus those that had undergone atresia repair [45]. However, in that study, because preoperative hearing varied drastically between the groups, the primary endpoint was gain in air conduction thresholds. Not surprisingly, those patients with poorer preoperative hearing (patients selected for $\mathrm{BAHA}^{\circledR}$ ) showed greater hearing gain. In general, there has been little evidence that suggests significant improvement with a bone anchored hearing device over the unaided condition in patients with unilateral CAA [46•*].
As the functional deficits of a unilateral conductive hearing loss become better understood, there may be an increased role for early bone conducting amplification in patients with unilateral aural atresia.

\section{Implantable Devices}

In addition to osseointegrated hearing devices, there are other implantable options for habilitating the atretic ear. First developed in the 1970s, active middle ear implants (AMEIs) convert acoustic energy to a mechanical stimulus and have been used to treat sensorineural, conductive and mixed hearing losses [47]. For conductive and mixed hearing losses, it is imperative that the pathology is not readily amenable to surgical correction. However, with inconsistent and sometimes mediocre hearing results with both ossicular and external ear canal reconstruction, these devices may provide an alternative to reconstructive surgery in some patients. There are many potential benefits to middle ear implants including improved gain and fidelity over conventional hearing aids. For patients not candidates for a conventional hearing aid, there is a reduced need for wound maintenance and improved cosmesis relative to BAHA ${ }^{\circledR}$.

The most commonly employed devices for patients with CAA are active middle ear implants using a floating mass transducer (FMT). In patients with CAA with malformed and often fixed ossicles, the FMT transducer can be placed directly on the round widow (FMT-RW) rather than coupled to the ossicular chain [48•]. Implantation can be challenging given the high variability of facial nerve position, middle ear size, and mastoid pneumatization [49]. Nevertheless, implantation of middle ear devices is far less technically demanding than atresia repair as it does not require eardrum grafting, placement of a split thickness skin graft or meatoplasty. Much like a cochlear implant, the FMT is wired to an internal receiver placed in a well in the squamosa away from the drilled area. Again, like a cochlear implant, the patient wears a sound processor wired to an external transmitter that "talks" to the internal receiver through a magnetic induction coil.

One example of a semi-implantable AMEI using the FMT is the Vibrant SoundBridge ${ }^{\circledR}$ (VSB; Med-El Hearing Technology, Innsbruck, Austria), which was FDA-approved for use in the US in 2000. Since that time, several studies have evaluated the efficacy of FMT-RW implantation on patients with middle and external ear malformations [48, 50-52]. Colletti, et al., published on a series of 12 patients with CAA ranging in age from 3 months to 31 years who had been implanted with a round window FMT device. These patients either were not considered candidates for atresia repair or had previously failed surgical reconstruction. Mean 
postoperative air conduction threshold for the group was 28.7 dB HL and there were no major complications [48•]. In another series of 14 patients with CAA implanted with the FMT-RW, the mean postoperative air conduction threshold was $24 \mathrm{~dB} \mathrm{HL}$ and a mean air-bone gap of $3 \mathrm{~dB} \mathrm{HL}$ at 12 months follow up [53]. A recent series from Verhaert et al. [54] demonstrated similar postoperative hearing results among patients implanted with the either the VSB on the stapes capitulum or with another AMEI, the Carina MET (Otologics, Boulder, CO).

Studies from Europe indicate that active middle ear implants are a safe and reliable way to amplify the atretic ear. In addition, there are significant wound care and cosmetic advantages when compared to osseointegrated devices in patients not considered optimal candidates for atresia repair surgery (Table 1). For patients with UAA not considered candidates for surgical reconstruction, AMEIs provide a reasonable alternative to osseointegrated devices [55].

\section{Timing of Intervention}

The timing of definitive management of UAA is usually not until the 5-6th year, and depends on the concurrent presence of microtia and the type of microtia repair. For patients who elect to have an osseointegrated bone conducting hearing aid implanted, this represents an obligatory wait period as these devices are not FDA-approved in patients less than 5 years of age. For patients with microtia who choose to undergo atresiaplasty, this is usually performed after the final stage of costal cartilage autograft reconstruction of the auricle. As mentioned, there has been recent suggestion that atresia repair and auricular reconstruction may be performed concurrently [26, 27]. If a patient elects to have the auricle reconstructed with a porous polyethylene allograft, the atresia repair may precede auricular reconstruction. However, even in this instance, atresia repair should be delayed until at least the age of 5 when the child has reached a certain level of maturity and can cooperate with the necessary canal cleaning required after surgery.

Given the delay in restoring binaural hearing, the question arises of what, if anything, should be done for patients with UAA that are too young for definitive hearing rehabilitation surgery. As mentioned previously, the functional impairments of a unilateral conductive hearing loss are less than those associated with a bilateral hearing loss. As such, patients with bilateral CAA are strongly advised to be fitted with a bone conducting hearing aid, such as the BAHA $^{\circledR}$ or Ponto ${ }^{\circledR}$ softband, at an early age. In contrast, among patients with UAA, the question of whether to amplify the atretic ear has largely been unanswered. There have been no studies evaluating the efficacy of amplification with a bone conducting hearing aid over the unaided condition in patients with UAA. Among children with a unilateral CHL, a hearing aid seems to improve hearing in noise but does not improve localization [56]. It remains unclear how the early deprivation of binaural input affects central processing once the hearing has been restored, though there is some evidence that there may be long-term effects [18, 57]. Early fitting with a bone conducting hearing aid softband may provide marginal benefits in binaural processing. However, these devices may be costly for families, are sometimes difficult to keep on a young

Table 1 Advantages and disadvantages of options for hearing rehabilitation for patients with unilateral aural atresia

\begin{tabular}{|c|c|c|c|c|c|c|}
\hline Treatment & Hearing & $\begin{array}{l}\text { Technical } \\
\text { ease of } \\
\text { surgery }\end{array}$ & Complications & Risk & Cosmesis & Wound care \\
\hline $\begin{array}{l}\text { Observation/ } \\
\text { preferential } \\
\text { seating/IEP }\end{array}$ & Poor no binaural & N/A & N/A & None & $\begin{array}{l}\text { Fair (no external } \\
\text { hardware, no } \\
\text { meatus) }\end{array}$ & N/A \\
\hline Atresia repair & $\begin{array}{l}\text { Excellent but variable; } \\
\text { 64-89\% with SRT } \\
\leq 30 \mathrm{~dB} \text { HL }[19,20]\end{array}$ & Difficult & $\begin{array}{l}\text { EAC stenosis, infection; } \\
\text { SNHL, facial n. injury } \\
\text { rare }\end{array}$ & Moderate & $\begin{array}{l}\text { Excellent (no } \\
\text { external } \\
\text { hardware, } \\
\text { normal meatus) }\end{array}$ & EAC debridement \\
\hline BAHA $^{\circledR}$ & Excellent, less variable & Easy & $\begin{array}{l}\text { Skin overgrowth, soft } \\
\text { tissue infection } \\
\text { common }\end{array}$ & Low & Poor & $\begin{array}{l}\text { Frequent wound care; } \\
\text { avoidance of trauma to } \\
\text { post }\end{array}$ \\
\hline AMEI & $\begin{array}{l}\text { Excellent; mean } \\
\text { postoperative AC } \\
\text { thresholds } 24-28 \mathrm{~dB} \text { HL } \\
{[43,48 \bullet]}\end{array}$ & Moderate & $\begin{array}{l}\text { Dizziness }[45,48 \bullet, 49] ; \\
\text { theoretical risk of } \\
\text { SNHL, facial n. injury }\end{array}$ & Moderate & $\begin{array}{l}\text { Moderate } \\
\text { (external } \\
\text { processor, no } \\
\text { meatus) }\end{array}$ & $\begin{array}{l}\text { Little, no canal; } \\
\text { avoidance of trauma to } \\
\text { site of internal } \\
\text { receiver }\end{array}$ \\
\hline
\end{tabular}

IEP individualized educational program, $S R T$ speech reception threshold, $d B H L$ decibels hearing level, $E A C$ external auditory canal, $S N H L$ sensorineural hearing loss, $A M E I$ active middle ear implant, $A C$ air conduction

Adapted from [41], with permission 
child and may be a source of some social stigma for a young child. Given the relative paucity of data indicating a significant functional improvement with early amplification of a unilaterally atretic ear, the decision to place a bone conducting hearing aid on a child with UAA is an individual one with input from the otolaryngologist, audiologist and family.

\section{Conclusion}

Unilateral aural atresia (UAA) remains a challenging clinical entity for the otologic surgeon. As our understanding of the functional deficits of a unilateral conductive loss has improved, there is a renewed focus on providing early hearing habilitation in these patients. Postoperative hearing results are good among patients who undergo atresia repair, though the surgery is technically demanding, not all children are candidates, and most published results come from centers that perform large numbers of these cases. Long-term hearing results after atresia surgery are needed. In smaller centers and for patients not considered candidates for surgical reconstruction, osseointegrated and active middle ear implants have offered encouraging results. Advancements in the ability to preoperatively select optimal candidates for surgical reconstruction will aid the clinician in counseling patients with unilateral CAA and their families. More studies are needed, however, especially in comparing results between treatment options and in those focusing on academic performance in children, binaural processing, patient satisfaction, and quality of life measures.

Disclosure No potential conflicts of interest relevant to this article were reported.

\section{References}

Papers of particular interest, published recently, have been highlighted as:

- Of importance

•- Of major importance

1. House HP. Management of congenital ear canal atresia. Laryngoscope. 1953;63:916-46.

2. Jahrsdoerfer RA. Congenital atresia of the ear. Laryngoscope. 1978;88:1-48.

3. Granstrom G, Bergstrom K, Tjellstrom A. The bone-anchored hearing aid and bone-anchored epithesis for congenital ear malformations. Otolaryngol Head Neck Surg. 1993;109:46-53.

4. Bellucci RJ. Congenital aural malformations: diagnosis and treatment. Otolaryngol Clin North Am. 1981;14:95-124.

5. Hasso AN, Broadwell RA. Congenital anomalies. In: Som PM, Bergeron RT, editors. Head and neck imaging. St Louis: Mosby; 1991. p. 960-6.
6. Vrabec JT, Lin JW. Inner ear anomalies in congenital aural atresia. Otol Neurotol. 2010;31:1421-6.

7. Altmann F. Congenital atresia of the ear in man and animals. Ann Otol Rhinol Laryngol. 1955;64:824-58.

8. De la Cruz A, Linthicum FH Jr, Luxford WM. Congenital atresia of the external auditory canal. Laryngoscope. 1985;95:421-7.

9. Jahrsdoerfer RA, Yeakley JW, Aguilar EA, et al. Grading system for the selection of patients with congenital aural atresia. Am J Otol. 1992;13:6-12.

10. Bess FH, Tharpe AM. Unilateral hearing impairment in children. Pediatrics. 1984;74:206-16.

11. Lieu JE. Speech-language and educational consequences of unilateral hearing loss in children. Arch Otolaryngol. 2004;130: 524-30.

12. Tharpe AM. Unilateral and mild bilateral hearing loss in children: past and current perspectives. Trends Amplif. 2008;12:7-15.

13. Lieu JE, Tye-Murray N, Karzon RK, Piccirillo JF. Unilateral hearing loss is associated with worse speech-language scores in children. Pediatrics. 2010;125:e1348-55.

14. Lieu JE, Tye-Murray N, Fu Q. Longitudinal study of children with unilateral hearing loss. Laryngoscope. 2012;122:2088-95.

15. Kunst SJ, Leijendeckers JM, Mylanus EA, et al. Bone-anchored hearing aid system application for unilateral congenital conducting hearing impairment: audiometric results. Otol Neurotol. 2008;29:2-7.

16. Ito K. Can unilateral hearing loss be a handicap in learning? Arch Otolaryngol Head Neck Surg. 1998;124:1389-90.

17. Priwin C, Jonsson R, Magnusson L, et al. Audiological evaluation and self-assessed hearing problems in subjects with single-sided congenital external ear malformations and associated conductive hearing loss. Int J Audiol. 2007;46:162-71.

18. Wilmington D, Gray L, Jahrsdoerfer R. Binaural processing after corrected congenital unilateral conductive hearing loss. Hear Res. 1994;74:99-114.

19. Lascaratos J, Assimakopoulos D. From the roots of otology: diseases of the ear and their treatment in Byzantine times (324-1453 ad). Am J Otol. 1999;20:397-402.

20. Lund R. Fenestration in congenital aural aplasia. Ugeskr Laeger. 1951;113:1593-7.

21. Ungerecht K. Technic of surgery for hearing improvement in severe aural deformities. Arch Ohren Nasen Kehlkopfheilkd. 1955;167:619-22.

22. Nager GT. Congenital aural atresia: anatomy and surgical management. Birth Defects Orig Artic Ser. 1971;7:33-51.

23. Schuknecht HF. Reconstructive procedures for congenital aural atresia. Arch Otolaryngol. 1975;101:170-2.

24. Goldsztein H, Ort S, Roberson JB, et al. Scalp as split thickness skin graft donor site for congenital atresia repair. Laryngoscope. 2012;123(2):496-8.

25. Roberson JB Jr, Reinisch J, Colen TY, et al. Atresia repair before microtia reconstruction: comparison of early with standard surgical timing. Otol Neurotol. 2009;30:771-6.

26. Siegert R. Combined reconstruction of congenital auricular atresia and severe microtia. Adv Otorhinolaryngol. 2010;68:95-107.

27. Zhao S, Wang D, Han D, et al. Integrated protocol of auricle reconstruction combined with hearing reconstruction. Acta Otolaryngol. 2012;132:829-33.

28. - Shonka DC Jr, Livingston WJ 3rd, Kesser BW. The Jahrsdoerfer grading scale in surgery for congenital aural atresia. Arch Otolaryngol Head and Neck Surg. 2008;134:873-7. Showed that postoperative hearing correlates with Jahrsdoerfer score, further validating the scale as a useful tool in preoperative counseling.

29. Lambert PR. Congenital aural atresia: stability of surgical results. Laryngoscope. 1998;108:1801-5.

30. De La Cruz A, Teufert KB. Congenital aural atresia surgery: long-term results. Otolaryngol Head Neck Surg. 2003;129:121-7. 
31. Teufert KB, De La Cruz A. Advances in congenital aural atresia surgery: effects on outcome. Otolaryngol Head Neck Surg. 2004; 131:263-70.

32. Ren Y, Zhao S, Wang D. Development and validation of a multidimensional quality of life questionnaire for congenital aural atresia. Acta Otolaryngol. 2012;132:708-14.

33. Oliver ER, Hughley BB, Shonka DC, et al. Revision aural atresia surgery: indications and outcomes. Otol Neurotol. 2011;32: $252-8$.

34. Moon IJ, Cho YS, Park J, et al. Long-term stent use can prevent postoperative canal stenosis in patients with congenital aural atresia. Otolaryngol Head Neck Surg. 2012;146:614-20.

35. - Oliver ER, Lambert PR, Rumboldt A, et al. Middle ear dimensions in congenital aural atresia and hearing outcomes after atresiaplasty. Otol Neurotol. 2010;31:946-53. Provides evidence that the radiographic dimensions of the middle ear can predict hearing success following atresia repair.

36. Osborn AJ, Oghalai JS, Vrabec JT. Middle ear volume as an adjunct measure in congenital aural atresia. Int $\mathbf{J}$ Pediatr Otorhinolaryngol. 2011;75:910-4.

37. Nicholas BD, Krook KA, Gray LC, et al. Does preoperative hearing predict postoperative hearing in patients undergoing primary aural atresia repair? Otol Neurotol. 2012;33:1002-6.

38. Dedhia K, Yellon RF, Branstetter BF, et al. Anatomic variants on computed tomography in congenital aural atresia. Otolaryngol Head Neck Surg. 2012;147:323-8.

39. - Kim DW, Lee JH, Song JJ, et al. Continuity of the incudostapedial joint: a novel prognostic factor in postoperative hearing outcomes in congenital aural atresia. Acta Otolaryngol. 2011; 131:701-7. Offers a new radiographic method for determining which patients are most likely to achieve good postoperative hearing after aural atresia repair.

40. Hakansson B, Liden B, Tjellstrom A, et al. The bone-anchored hearing aid: principles, design and a psychoacoustical evaluation. Acta Otolaryngol. 1985;100:229-39.

41. Yellon RF. Atresiaplasty versus BAHA for congenital aural atresia. Laryngoscope. 2010;121:2-3.

42. van der Pouw KT, Snik AF, Cremers CW. Audiometric results of bilateral bone-anchored hearing aid application in patients with bilateral congenital aural atresia. Laryngoscope. 1998;108: 548-53.

43. Ricci G, Della Volpe A, Farali M. Results and complications of the Baha system (bone-anchored hearing aid). Eur Arch Otorhinolaryngol. 2010;267:1539-45.

44. Ricci G, Volpe AD, Farali M, et al. Bone-anchored hearing aids (Baha) in congenital aural atresia: personal experience. Int $\mathrm{J}$ Pediatr Otorhinolaryngol. 2011;75:342-6.
45. Bouhabel S, Arcand P, Saliba I. Congenital aural atresia: boneanchored hearing aid vs. external auditory canal reconstruction. Int J Pediatr Otorhinolaryngol. 2012;76:272-7.

46. •- Danhauer JL, Johnson CE, Mixon M. Does the evidence support the use of the Baha implant system (Baha) in patients with congenital unilateral aural atresia? J Am Acad Audiol. 2010;21:274-86. Review of several published reports to evaluate whether there is sufficient evidence to support BAHA implantation over the unaided condition in patients with UAA.

47. Fredrickson JM, Tomlinson DR, Davis ER, et al. Evaluation of an electromagnetic implantable hearing aid. Can J Otolaryngol. 1973;2:53-62.

48. - Colletti L. Carner M, Mandalá M, et al. The floating mass transducer for external auditory canal and middle ear malformations. Otol Neurotol. 2011;32:108-15. Initial series evaluating the efficacy of AMEIs in patients with CAA. Though a small series, the study demonstrates that FMT-RW devices are safe and provide satisfactory hearing results in this population.

49. Barillari M, Cerini R, Carner M, et al. Congenital aural atresia treated with floating mass transducer on the round window: 5 years of imaging experience. Radiol Med. 2012;117:488-99.

50. Frenzel H, Hanke F, Beltrame M, et al. Application of the Vibrant Soundbridge to unilateral osseous atresia cases. Laryngoscope. 2009;119:67-74.

51. Dumon T, Gratacap B, Firmin F, et al. Vibrant Soundbridge middle ear implant in mixed hearing loss. Indications, techniques and results. Rev Laryngol Otol Rhinol. 2009;130:75-81.

52. Cuda D, Murri A, Tinelli N. Piezoelectric round window osteoplasty for Vibrant Soundbridge implant. Otol Neurotol. 2009;30: 782-6.

53. Mandalá M, Colletti L, Colletti V. Treatment of the atretic ear with round window Vibrant Soundbridge implantation in infants and children: electrocochleography and audiologic outcomes. Otol Neurotol. 2011;32:1250-5.

54. Verhaert N, Fuchsmann C, Tringali S, et al. Strategies of active middle ear implants for hearing rehabilitation in congenital aural atresia. Otol Neurotol. 2011;32:639-45.

55. Frenzel H, Schöweiler R, Hanke F, et al. The Lübeck flowchart for functional and aesthetic rehabilitation of aural atresia and microtia. Otol Neurotol. 2012;33:1363-7.

56. Priwin C, Jonsson R, Hultcrantz M, et al. BAHA in children and adolescents with unilateral or bilateral conductive hearing loss. Int J Pediatr Otorhinolaryngol. 2007;71:135-45.

57. Gray L, Kesser BW, Cole E. Understanding speech in noise after correction of congenital unilateral aural atresia: effects of age in the emergence of binaural squelch but not in use of head shadow. Int J Pediatr Otorhinolaryngol. 2009;73:1281-7. 